\title{
Multi-walled Carbon Nanotube Filled Polypropylene Nanocomposites: Electrical, Mechanical, Rheological, Thermal and Morphological Investigations
}

\author{
Nawadon Petchwattana ${ }^{\mathrm{a}, *}$, Sirijutaratana Covavisaruch $^{\mathrm{b}}$, Katabongkot Phetsang $^{\mathrm{b}}$ \\ ${ }^{a}$ Division of Polymer Materials Technology, Faculty of Agricultural Product Innovation and Technology, \\ Srinakharinwirot University, Sukhumvit 23, Wattana, Bangkok 10110, Thailand. \\ ${ }^{\mathrm{b}}$ Department of Chemical Engineering, Faculty of Engineering, Chulalongkorn University, \\ Pathumwan, Bangkok 10330, Thailand.
}

*Corresponding Author: nawadon@g.swu.ac.th

\begin{abstract}
The present research aims to investigate the mechanical, rheological, thermal, electrical and morphological properties of nanocomposites prepared from polypropylene (PP) and multi-walled carbon nanotube (MWCNT) whose content was varied from 1-6wt $\%$. The electrical resistance of the PP/MWCNT decreased dramatically with the addition of the MWCNT; the PP/MWCNT showed an electrical percolation threshold at the MWCNT content of 1 $\mathrm{wt} \%$. The relative viscosity was reduced as the shear rate and temperature increased. The thermal properties of the PP/MWCNT and the crystallization temperature were raised significantly with the MWCNT loading but the degree of crystallinity remained unchanged. The tensile modulus of the PP/MWCNT increased significantly with the presence of the MWCNT while the impact energy increased with the MWCNT loading.
\end{abstract}

Keywords: Polymer nanocomposites; Carbon nanotube; Electrical properties; Mechanical properties.

\section{Introduction}

In the last decades, small scaled carbon materials such as carbon nanotube (CNT) have generated much attention from both research institutions and industries due to their outstanding performances especially when they are incorporated into polymer matrices [1]. This was believed to be the results of their extremely high surface area, modulus and strength [2-3]. Numerous literatures have found that the mechanical properties of polymers, especially modulus and strength can be enhanced by incorporating only a small amount of CNT [4]. Therefore CNT has been utilized as reinforcement in polymers to form nanocomposite materials [5] in engineering applications.

Polypropylene (PP) is one of the most important commodity plastics; it is generally used in the plastic industry to produce bottles, films, sheets or fibers [6]. Unfortunately, the application of PP has restricted by its softness at ambient temperature, its brittleness at low temperatures and its insulation properties [7]. Thus, many attempts have been made to improve the performances of $\mathrm{PP}$ or to achieve new properties of the PP composites [4-7]. Composite materials based on PP and CNT have gained much attention in the path of developing new materials. In many observations, the property enhancement was investigated by studying the electrical [8], mechanical [2], thermal [7] and other properties [9]. The flexural modulus of the PP/CNT composites was found to increase from 1.28 to $2.15 \mathrm{GPa}$ when the CNT was add at $5.0 \mathrm{wt} \%$ [2]. Significant improvement in the crystallization was found when the CNT was added at only $0.5 \mathrm{wt} \%$ [10]. Moreover, it was reported that the electrical percolation could occur at very low CNT content of $0.05 \mathrm{vol} \%$ [11].

The present study aims to investigate the effects of multi-walled carbon nanotubes (MWCNT) on the mechanical, thermal, rheological, electrical and 
morphological properties of PP/MWCNT composites. Each formulation of the PP/MWCNT was processed by using a twin screw extruder with the MWCNT content varied from $1-6 w t \%$ at different melt-blending screw speeds of 200 and $270 \mathrm{rpm}$.

\section{Experimental Works}

\subsection{Raw Materials}

Polypropylene (PP) (Polimaxx 1100RC) with a melt flow index (MFI) of $20 \mathrm{~g} / 10 \mathrm{~min}$ at $230^{\circ} \mathrm{C}$ was obtained from IRPC Public Company Limited (Bangkok, Thailand). The masterbatch of MWCNT (Plasticyl-2001), containing $20 \mathrm{wt} \%$ of MWCNT was provided by Siam Extek Company Limited, Thailand. The MWCNT masterbatch contained the nanotubes with average diameter of $9.5 \mathrm{~nm}$ and average length of $1.5 \mu \mathrm{m}$. The purity of the masterbatch was over $90 \%$.

\subsection{Preparation of the PP/MWCNT composites}

The initial MWCNT masterbatch concentration was diluted to 1, 2, 4 and $6 \mathrm{wt} \%$ by melt blending with a neat PP. Each formulation of the PP/MWCNT was processed by using a twin screw extruder (HAAKE minilab II) with different melt-blending at the re-circulation residence time of $15 \mathrm{~min}$ and at the screw speeds of 200 and 270rpm at $200^{\circ} \mathrm{C}$. Both speeds covered the range appropriate for the PP with MFI 20g/10 min selected for the present study and yielded the residence of $15 \mathrm{~min}$ for melt blending within the extruder. After extrusion, the PP/MWCNT composites were injected by using the injection molding machine (Thermo Sciencetific HAAKE MiniJet II) to obtain specimens for subsequence tests.

\subsection{Testing and characterizations}

A dielectric constant $(K)$ is an important parameter indicating the capability of the materials to store the electrical energy. In the current research, the dielectric constant was evaluated by using the Agilent E4980A Precision LCR Meter according to the method described in ASTM D 150 [12]. The test was conducted at 1 volt for 60 seconds. The $\mathrm{K}$ value was calculated by using Equation (1).

$$
C=K \varepsilon_{0} \frac{A}{d}
$$

where $C$ is the capacitance, $K$ is the dielectric constant, $A$ is the cross sectional area of the test specimen $\left(\mathrm{mm}^{2}\right), \mathrm{d}$ and $\varepsilon_{0}$ are the thickness of the specimen $(\mathrm{mm})$ and permittivity of vacuum $(0.0088542 \mathrm{pF} / \mathrm{mm})$ respectively.
The electrical resistivity was determined in accord with ASTM D 257 by using a high resistance meter (Agilent 4339B) and a source meter (Keithley source meter 2420). Equation (2) was applied in order to calculate the electrical resistivity $(\rho, \Omega . c m)$ of the neat PP and the PP/MWCNTs composites.

$$
\rho=R \frac{A}{l}
$$

where $R$ is the electrical resistance of the material $(\Omega), l$ is the length of the test specimen $(\mathrm{cm})$ and $A$ is the cross-sectional area of the test specimen $\left(\mathrm{cm}^{2}\right)$.

The transition temperatures namely glass transition temperature $\left(\mathrm{T}_{\mathrm{g}}\right)$, crystallization temperature $\left(\mathrm{T}_{\mathrm{c}}\right)$ and melting temperature $\left(\mathrm{T}_{\mathrm{m}}\right)$ of the PP/MWCNT composites were evaluated by using a Differential Scanning Calorimeter (DSC, Mettler Toledo). The test was run from -30 to $200^{\circ} \mathrm{C}$ (cooling from 25 to $-30 \mathrm{oC}$, holding for $10 \mathrm{~min}$, heating from -30 to $200^{\circ} \mathrm{C}$, holding for $10 \mathrm{~min}$, cooling from 200 to $-30^{\circ} \mathrm{C}$, holding for $10 \mathrm{~min}$ and re-heating from -30 to $200^{\circ} \mathrm{C}$ ) at the heating rate of $10 \mathrm{oC} / \mathrm{min}$ under nitrogen atmosphere.

The degree of crystallinity $\left(\mathrm{X}_{\mathrm{c}}\right)$ of the PP/MWCNT composites was evaluated from the DSC scans and calculated by using Equation (3) [13].

$$
X_{C}(\%)=100 \frac{\Delta H_{m}}{\Delta H_{f} \times X_{P P}}
$$

where $\Delta \mathrm{H}_{\mathrm{m}}$, and $X_{P P}$ are the enthalpy of melting, the weight fraction of the PP respectively. $\Delta \mathrm{H}_{\mathrm{f}}$ is the heat of fusion, defined as the melting enthalpy of $100 \%$ crystalline PP homopolymer, which was $190 \mathrm{~J} / \mathrm{g}$ [14].

The tensile test was conducted by using a universal testing machine (INSTRON, 5567) at room temperature according to the procedure described in ASTM D 638. The notched Izod impact strength of the nanocomposites was determined following ASTM D 256 by using an impact tester (Yasuda, 258PC) at room temperature. A three-point bending test with a support span of $48 \mathrm{~mm}$ was carried out by using a Universal Testing Machine (INSTRON, 5567) at room temperature and the crosshead speed was set at 12 $\mathrm{mm} / \mathrm{min}$. Hardness test was conducted by using Rockwell Hardness tester $R$ Scale with a 0.5 in ball penetrator (Identec hardness tester). A minor load of $10 \mathrm{~kg}$ was first applied on the PP/MWCNT surfaces to obtain the primary imprint. A $50 \mathrm{~kg}$ major load was then applied to the test specimen in order to evaluate the Rockwell hardness number.

The shear viscosity of the PP/MWCNT was measured by using a twin screw extruder (HAAKE minilab II). The relative viscosity and the shear rate at $200^{\circ} \mathrm{C}$ were recorded 
simultaneously.

Microscopic observation of the fractured surfaces of the PP/MWCNT composites was conducted by using a field-emission scanning electron microscope (FE-SEM) (Hitachi S-4700) at an accelerating voltage of $5 \mathrm{kV}$. The study was performed to investigate the fractured topology and the dispersion of the MWCNT in the PP matrix.

\section{Results and Discussion}

\subsection{Effects of MWCNT on the electrical properties of the PP/MWCNT nanocomposites}

The influence of concentration of the MWCNT and the screw speed on the electrical resistivity and the dielectric constant of PP/MWCNT composites are shown in Figs. 1 and 2 respectively. It is evident that the electrical resistivity was obviously affected by the MWCNT contents studied, leading to a wide range of resistivity from 1015 to $104 \Omega . \mathrm{cm}$. The electrical resistivity of the neat PP was $2.16 \times 10^{15} \Omega . \mathrm{cm}$ while the addition of only $1 \mathrm{wt} \%$ MWCNT drastically reduced the electrical resistivity by approximately 109 times. This implies that the concentration of conductive MWCNT played an essential role in the formation of conducting network in PP/MWCNT nanocomposites. Further increment of the MWCNT content did not lead to any significant reduction of the electrical resistivity due to the formation of MWCNT agglomeration, as illustrated in Fig. 6.

Dielectric constant data of the PP/MWCNT nanocomposites at different concentrations of MWCNT and screw speeds is presented in Fig. 2. The dielectric constant increased with the MWCNT content at all compositions studied. By adding only $1 \mathrm{wt} \%$ MWCNT, the dielectric constant of the nanocomposites increased around two times while the electrical resistivity decreased as shown in Fig. 1. When the MWCNT content reached $6 \mathrm{wt} \%$, the dielectric constant increased significantly by 15 and 16 times for the nanocomposites processed at speed 200 and 270rpm respectively. However, the dielectric constant values were found to be lower than those reported by Tjong et al. [17] and Bikiaris [16]. This was probably the consequence of the agglomerations of MWCNT formed in the nanocomposite, as illustrated in the FE-SEM micrograph in Fig. 6.

However, identical resistivity was found irrespective of the screw speed of 200rpm and 270rpm. Similar PP/MWCNT morphology and dispersion characteristic was observed at both speeds of screws during melt blending, this was illustrated in the FE-SEM micrographs enclosed in Fig. 1. The influences of the MWCNT content on the electrical properties of nanocomposites were observed by many researchers. The resistivity decrement was believed to have caused by the formation of conductive chains in the composites [15]. The percolating network of the MWCNT at all the concentrations tested seemed to have assumed random positions but MWCNTs were observed to have overlapped with other MWCNTs [16] and formed interconnected conductive pathway as enclosed in Fig. 1.

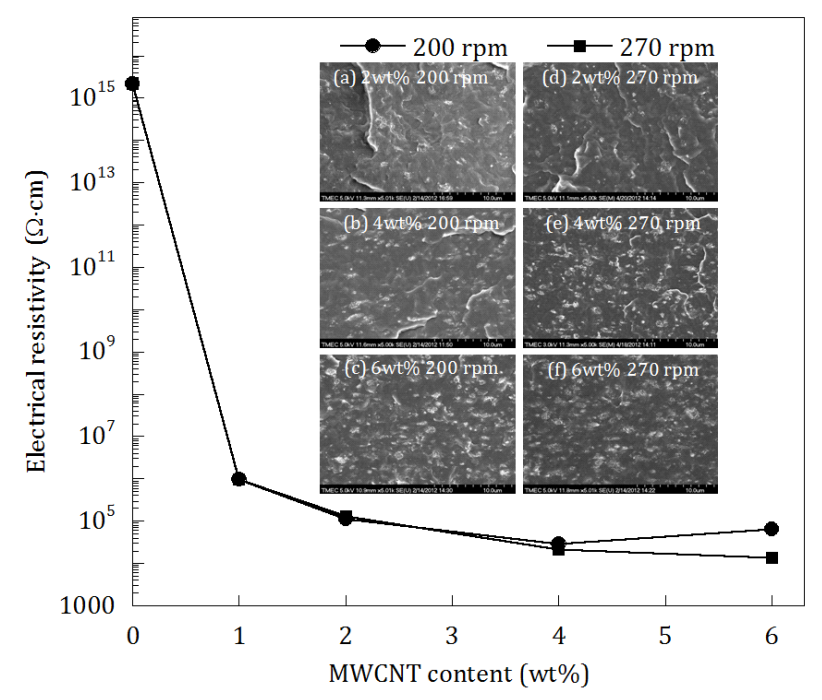

Fig. 1 Electrical resistivity of PP/MWCNT composites at the screw speed of 200 and $270 \mathrm{rpm}$.

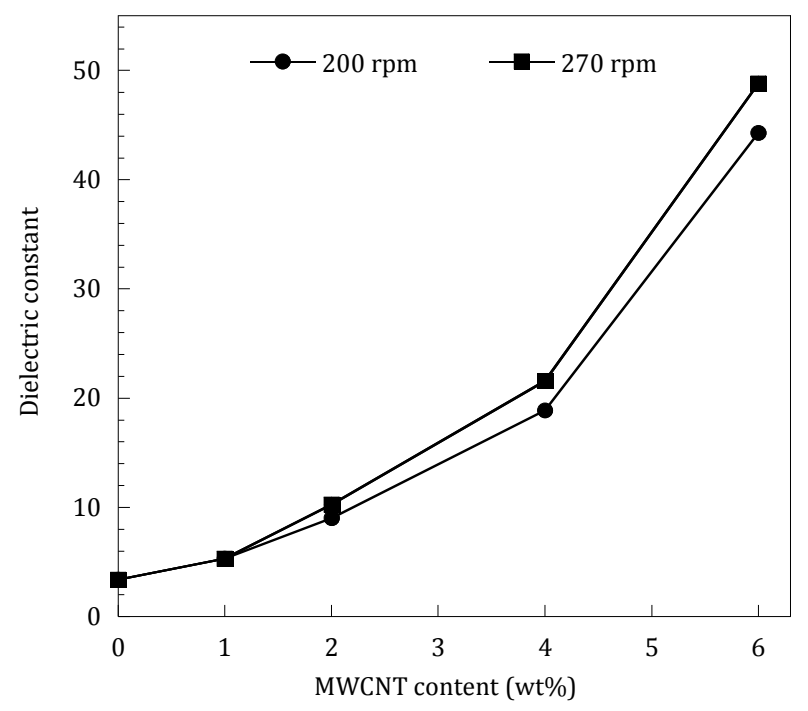

Fig. 2 Dielectric constant of PP/MWCNT composites at the screw speed of 200 and $270 \mathrm{rpm}$.

\subsection{Effects of MWCNT on the mechanical properties of the PP/MWCNT nanocomposites}

Tensile properties of the injection molded 
nanocomposites are shown in Fig. 3. The Young's modulus of the nanocomposites was found to have increased substantially compared with that of the neat iPP as illustrated in Fig. 3(a). The tensile modulus of PP/MWCNT increased with increasing MWCNT contents. It became stagnate at greater MWCNT content of 4-6 wt \%. This was due to the formation of some agglomerates at the MWCNT content of 4-6wt\%. The size of the MWCNT agglomerates was found to increase with increasing nanotube content. At low MWCNT contents, the nanotubes act as a reinforcing phase, but at higher MWCNT contents they tended to form agglomerates which adversely acted as mechanical failure concentrators.
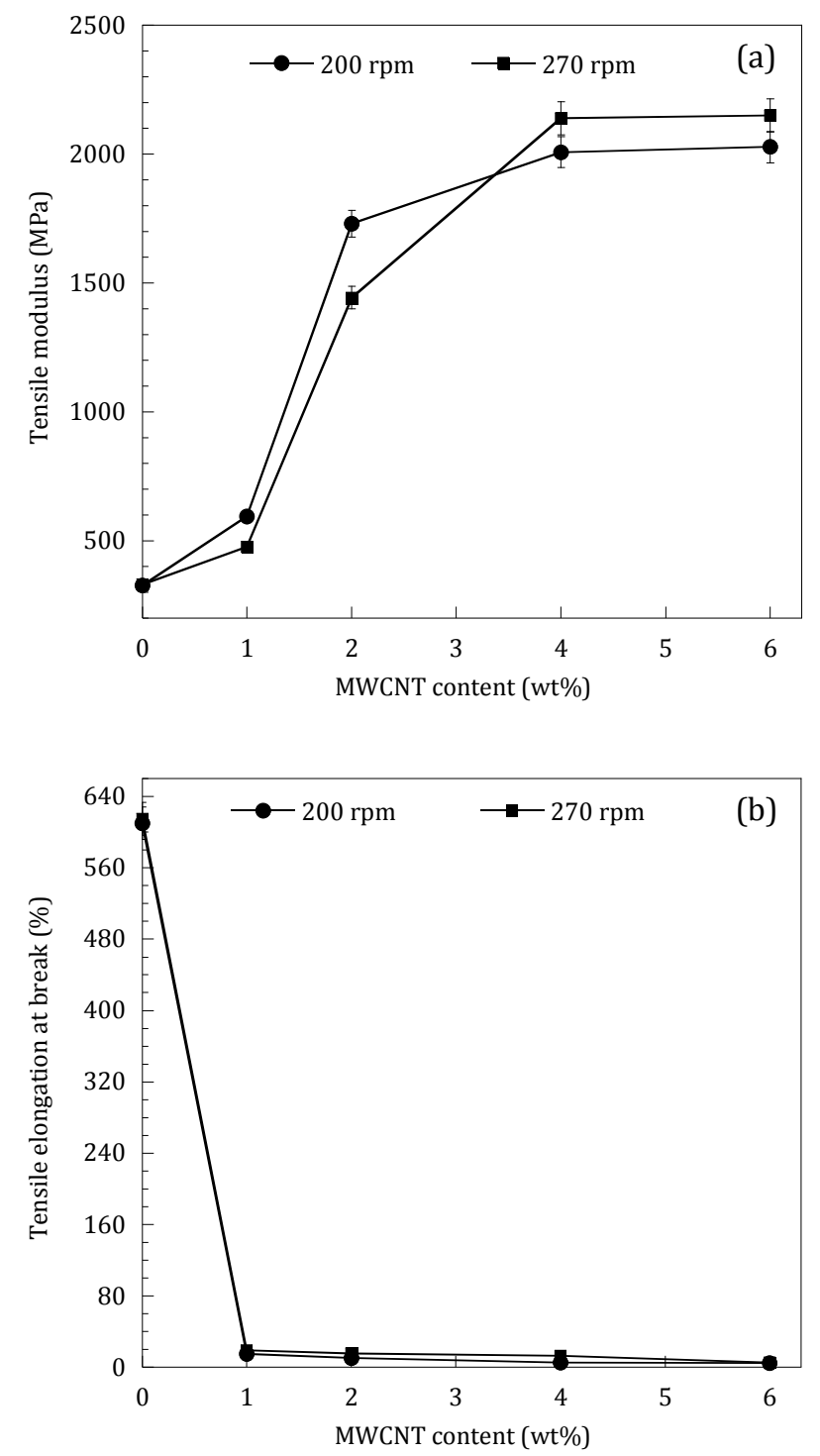

Fig. 3 Tensile properties of PP/MWCNT nanocomposites at the screw speed of 200 and $270 \mathrm{rpm}$ (a) tensile modulus and (b) tensile elongation at break.

Thus, PP/MWCNT nanocomposites exhibited their higher mechanical performance at the concentration of $1-4 \mathrm{wt} \%$ but further increase of the MWCNT led to a lower tensile strength of the nanocomposites. At low MWCNT content, partial tensile stress could be transferred to the MWCNT embedded in the PP matrix, leading to an increase of the tensile strength. With further addition of the MWCNT, it was difficult to disperse the MWCNT during melt mixing [16-17]. Hence, more agglomerates of MWCNT were formed in PP matrix; they acted like many defects in the PP matrix. In Fig. 3(b), the typical ductile behavior with a very high elongation at break of around 610 and $615 \%$ for the PP processed at 200 and $270 \mathrm{rpm}$ respectively changed drastically with the presence of MWCNT. The addition of only $1 \mathrm{wt} \%$ MWCNT led to dramatic reductions in the tensile elongation at break by 40 and 30times for PP/MWCNT nanocomposites processed at 200 and $270 \mathrm{rpm}$ respectively. It was believed that the numerous MWCNT obstructed the entanglement of the PP chains and lowered the tensile elongation at break.

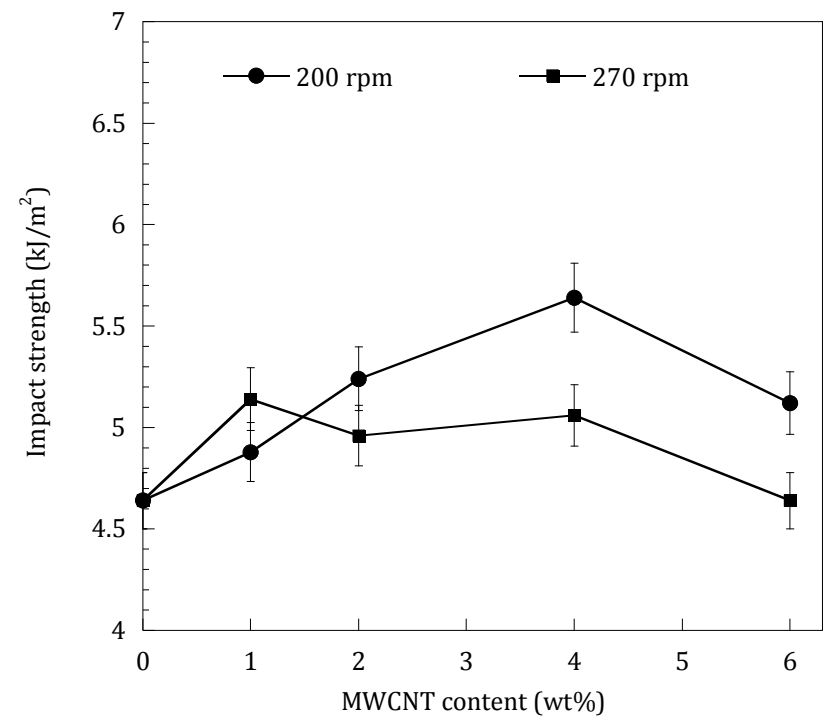

Fig. 4 Impact strength of PP/MWCNT composites at the screw speed of 200 and $270 \mathrm{rpm}$.

The impact strength of the notched PP/MWCNT samples is shown in Fig. 4. The impact resistance increased slightly with increasing MWCNT content. At low MWCNT concentration, the impact strength increased steadily reaching the maximum value over the MWCNT ranged 1-4 wt $\%$, depending on the melt mixing speed of the screw, and gradually decrease after that concentration. At $1 \mathrm{wt} \%$ MWCNT the impact strength was found to increase by 5 and $11 \%$ for the PP/MWCNT processed at 200 and $270 \mathrm{rpm}$ respectively. More pronounced decrease was observed at 6 wt $\%$ MWCNT content; this was also due to the presence of 
nanotube agglomerations in the PP matrix. They became the points of higher stress concentrations, thus providing sites for crack initiation [2]. The lower impact energy at higher nanotube content was due to the presence some masterbatch agglomerates in the composites [18] as shown in Fig. 6.

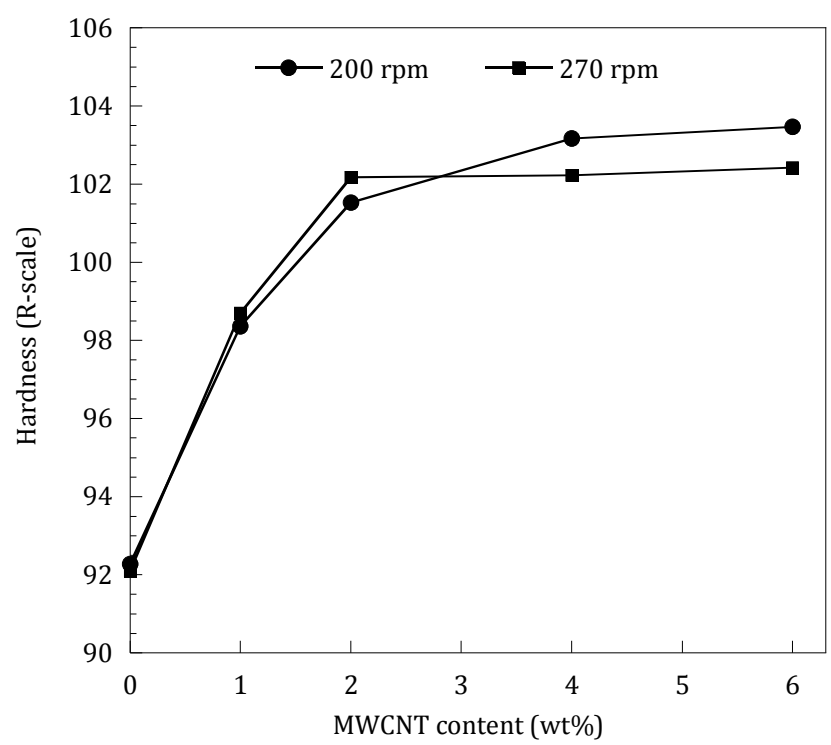

Fig. 5 Hardness of PP/MWCNT composites melt blended at the screw speed of 200 and $270 \mathrm{rpm}$.

Changes in the hardness of the PP and PP/MWCNT nanocomposites exhibited a similar trend as the tensile modulus as illustrated in Fig. 5. The hardness of the MWCNT reinforced PP composites was enhanced with increasing MWCNT content simply became the MWCNT was a much harder phase than the PP matrix. The hardness result was in agreement with those found in many nanocomposites having MWCNT as the reinforcing phase although the matrix studied was varied such as poly(methyl methacrylate) (PMMA) [19], epoxy [20], polyacrylonitrile (PAN) [21] and nitrile rubber [22].

The SEM micrographs of the PP/MWCNT composites with various MWCNT contents are illustrated in Fig. 6. The MWCNT agglomerates were found to partially infiltrate by the polymer matrix during melt-mixing. As illustrated in Fig. 6(a) and 6(e), at low MWCNT content, most of the MWCNTs dispersed well with only small clusters in the iPP matrix. At relatively high MWCNT content, more MWCNT agglomerates appeared in the PP matrix, the size of the agglomerates increased with increasing MWCNT content. The cluster sizes depended mainly on the MWCNT concentration. At low MWCNT content of 1 and $2 \mathrm{wt} \%$, the agglomerates were smaller in cluster. The mean cluster sizes were in the range of 0.2 up to $1 \mu \mathrm{m}$. As MWCNT content increased, MWCNT formed larger agglomerates than $1 \mu \mathrm{m}$. This was due to the surface forces of each MWCNT [16].
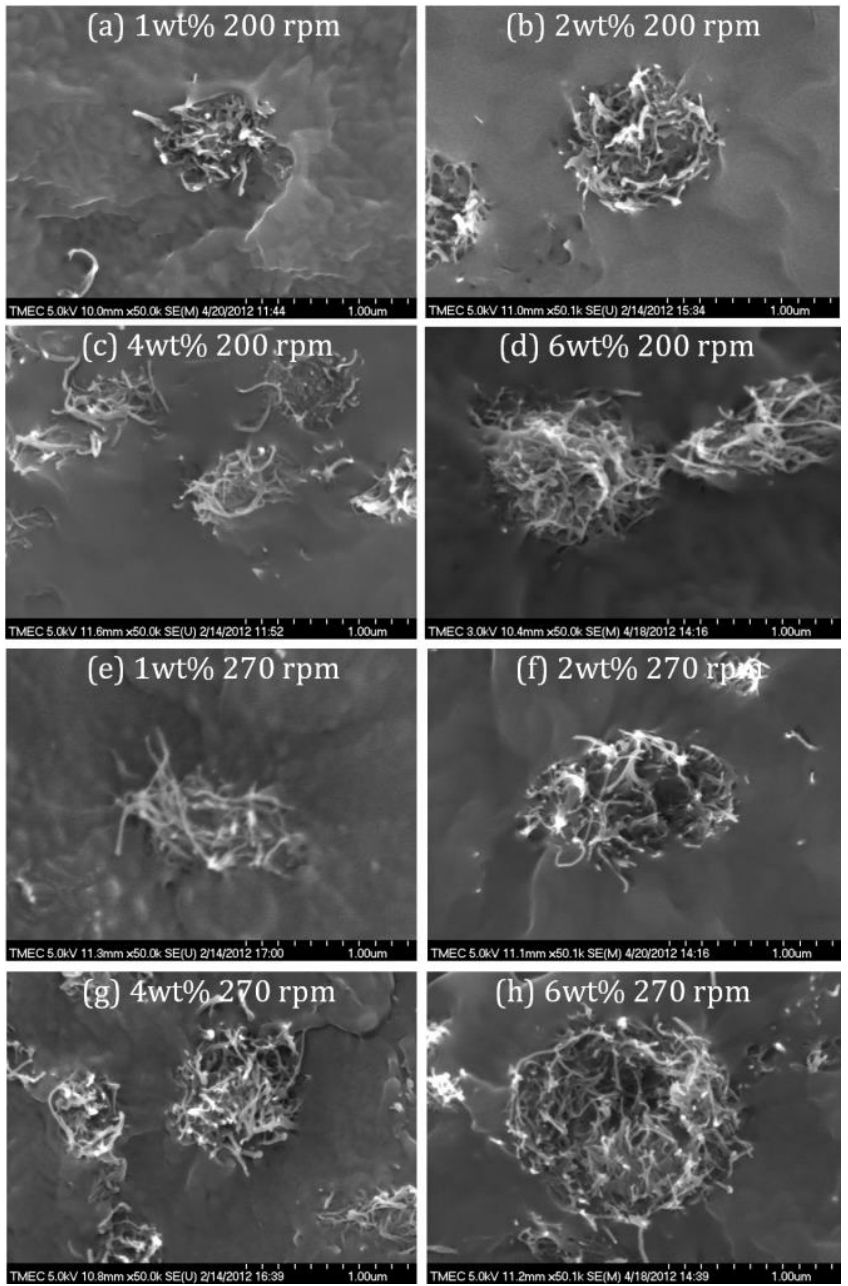

Fig. 6 SEM micrographs of iPP/MWCNT composites.

Fig. 7(a) and (b) shows the effect of the MWCNT content on the rheological properties of the PP/MWCNT composites processed at 200 and 270rpm respectively. Comparison of the melt viscosities indicated the significant effects of the MWCNT content. Over the shear rate range of $35-500 \mathrm{~s}^{-1}$, the molten PP/MWCNT composites showed higher viscosity compared with that of neat PP for both processing speeds of 200 and 270rpm. The PP/MWCNT was formed to exhibit a shear thinning character. The change of viscosity by the addition of MWCNT lied within this range of shear rate. The rise in the viscosity might have been due to the confinement of the PP chains due to the presence of numerous MWCNTs. However, at a higher shear rate of 500-960 s-1, the melt viscosity of PP/MWCNT was close to that of the neat PP.

Table 1 lists the temperatures of glass transition $\left(\mathrm{T}_{\mathrm{g}}\right)$, crystallization $\left(\mathrm{T}_{\mathrm{c}}\right)$, melting $\left(\mathrm{T}_{\mathrm{m}}\right)$ as well as the degree of crystallinity $\left(\mathrm{X}_{\mathrm{c}}\right)$ of the PP and PP/MWCNT 
nanocomposites. Both the incorporation of the MWCNT and the variation of the screw speed exerted insignificant effects on the $T_{g}, T_{m}$ and the $X_{c}$ of the PP. Interestingly, the shift of the $T_{c}$ to high temperatures was relatively small for the composites with lower MWCNT contents compared to those with higher MWCNT. Further increase of the MWCNT contents in the composites above $2 \mathrm{wt} \%$ led to a rapid rise of the $T_{c}$.
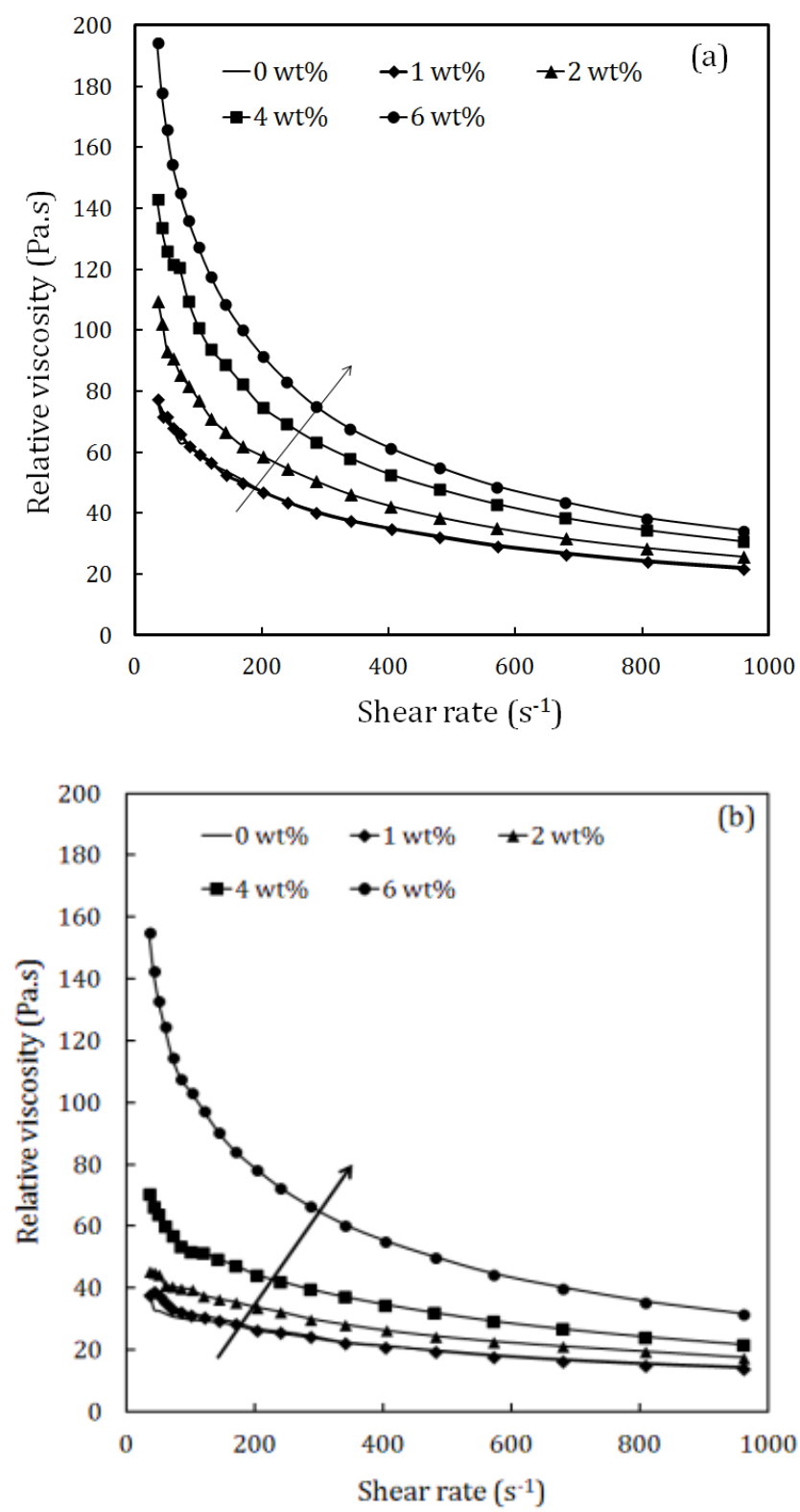

Fig. 7 Relative viscosities of iPP/MWCNT composites at the screw speed of (a) 200 and (b) $270 \mathrm{rpm}$.

The additions of MWCNT by $2 \mathrm{wt} \%$ produce a highly heterogeneous nucleation effect in the PP. Park et al. also reported that the addition more than $1 \mathrm{wt} \%$ MWCNT enhanced the nucleation process during PP crystallization [10]. With increasing the MWCNTs content, it has been found that the PP crystallinity could remain stable [23], decrease slightly [24] or increase [25].

Table 1 Transition temperatures and degree of crystallinity of PP/MWCNT nanocomposites.

\begin{tabular}{|c|c|c|c|c|c|c|}
\hline \multirow{2}{*}{$\begin{array}{l}\text { Transition } \\
\text { temperature }\end{array}$} & \multirow{2}{*}{$\begin{array}{l}\text { Screw } \\
\text { speed } \\
(\mathrm{rpm})\end{array}$} & \multicolumn{5}{|c|}{ MWCNTs content (wt\%) } \\
\hline & & PP & 1.0 & 2.0 & 4.0 & 6.0 \\
\hline \multirow{2}{*}{$\mathrm{T}_{\mathrm{g}}\left({ }^{\circ} \mathrm{C}\right)$} & 200 & -17.3 & -17.2 & -17.4 & -16.7 & -16.6 \\
\hline & 270 & -17.1 & -17.3 & -17.3 & -17.4 & -17.6 \\
\hline \multirow{2}{*}{$\mathrm{T}_{\mathrm{c}}\left({ }^{\circ} \mathrm{C}\right)$} & 200 & 116.1 & 128.0 & 128.8 & 131.3 & 131.9 \\
\hline & 270 & 116.0 & 127.4 & 129.8 & 132.2 & 133.2 \\
\hline \multirow{2}{*}{$\mathrm{T}_{\mathrm{m}}\left({ }^{\circ} \mathrm{C}\right)$} & 200 & 161.2 & 164.7 & 164.9 & 166.0 & 167.2 \\
\hline & 270 & 161.2 & 164.4 & 164.1 & 165.0 & 167.4 \\
\hline \multirow{2}{*}{$\mathrm{X}_{\mathrm{c}}(\%)$} & 200 & 46.8 & 47.3 & 47.7 & 47.0 & 45.9 \\
\hline & 270 & 46.8 & 49.3 & 46.2 & 45.1 & 45.0 \\
\hline
\end{tabular}

\section{Conclusions}

By adding only $1 \mathrm{wt} \%$ of MWCNT, the dielectric constant of the PP/MWCNT nanocomposites increased around two times while the electrical resistivity decreased. The tensile modulus and the hardness of the PP/MWCNT increased with increasing MWCNT contents. The modulus of the PP/MWCNT with $6 \mathrm{wt} \%$ MWCNT processed at both 200 and $270 \mathrm{rpm}$ were found to decline due to the formation of some MWCNT agglomerates. The molten PP/MWCNT composites show higher viscosity compared with that of the neat PP due to the shear thinning character. At low MWCNT content, the MWCNTs dispersed well within the PP matrix. At relatively high MWCNT contents, more MWCNT agglomerates appeared in the PP matrix. The size of the agglomerates increased with increasing MWCNT content.

\section{Acknowledgment}

The authors acknowledge the partial research funding provided by Thailand Research Fund (TRF). Generous provision of processing facilities at PTT Public Company Limited and IRPC Public Company Limited were greatly appreciated. Thanks are extended to Siam Extek Company Limited for supplying the MWCNT.

\section{References}

(1) Darunee Aussawasathien, Natcha Prakymoramas, and 
Dumrong ThanomjitrChiang : "Effects of reprocessin on the structure and properties of polycarbonate/multi-walled carbon nanotube based electrostatic dissipative composites", Chiang Mai Journal of Science, Vol. 40, No. 2, pp. 261-273, 2013

(2) Darunee Aussawasathien, and Chanpen Teerawattananon : "Preparation and properties of woven carbon fiber mat-epoxy composites containing dispersed base-functionalized multi-walled carbon nanotubes", Chiang Mai Journal of Science, Vol. 39, No. 3, pp. 524-539, 2012

(3) Paweena Sureeyatanapas, and Robert Young : "Deformation behavior of release agent coated glass fibre/epoxy composite using carbon nanotubes as strain sensors", Songklanakarin Journal of Science and Technology, Vol. 35, No. 1, pp. 51-56, 2013

(4) Russell E. Gorga, and Robert E. Cohen : "Toughness enhancements in poly(methyl methacrylate) by addition of oriented multiwall carbon nanotubes", Journal Polymer Science Part B Polymer Physics, Vol 42, No. 14, pp. 2690-2702, 2004

(5) Amal M.K. Esawi, and Mahmoud M. Farag : "Carbon nanotube reinforced composites: Potential and current challenges", Materials and Design, Vol. 28, No. 9, pp. 2394-2401, 2007

(6) Kessaraporn Trongtorsak, Pitt Supaphol, and Supawan Tantayanon : "Effect of calcium stearate and pimelic acid addition on mechanical properties of heterophasic isotactic polypropylene/ethylene-propylene rubber blend", Polymer Testing, Vol. 23, No. 5, pp. 533-539, 2004

(7) Donghua $\mathrm{Xu}$, and Zhigang Wang : "Role of multi-wall carbon nanotube network in composites to crystallization of isotactic polypropylene matrix", Polymer, Vol. 49, No. 1, pp. 330-338, 2008

(8) Seung Hwan Lee, EunNaRi Cho, So Hee Jeon, and Jae Ryoun Youn : "Rheological and electrical properties of polypropylene composites containing functionalized multi-walled carbon nanotubes and compatibilizers", Carbon, Vol. 45, No. 14, pp. 2810-2822, 2007

(9) Zdenko Spitalsky, Dimitrios Tasis, Konstantinos Papagelis, and Costas Galiotis : "Carbon nanotubepolymer composites: Chemistry, processing, mechanical and electrical properties", Progress in Polymer Science, Vol. 35, No. 3, pp. 357-401, 2010 357.

(10) Min Kang Seo, Jae Rock Lee, and Soo Jin Park : "Crystallization kinetics and interfacial behaviors of polypropylene composites reinforced with multi-walled carbon nanotubes", Materials Science and Engineering A, Vol. 404, No. 1-2, pp. 79-84, 2005

(11) Rodney Andrews, David Jacques, Dali Qian, and Terry Rantell : "Multiwall carbon nanotubes: Synthesis and application", Account of Chemical Research, Vol. 35, No. 12, pp. 1008-1017, 2002

(12) Hui Zhanga, and Zhong Zhang : "Impact behaviour of polypropylene filled with multi-walled carbon nanotubes", European Polymer Journal, Vol. 43, No. 8,, pp. 3197-3207, 2007

(13) S. C. Tjong, and S. P. Bao : "Impact fracture toughness of polyamide- $6 /$ montmorillonite nanocomposites toughened with a maleated styrene/ethylene butylene/styrene elastomer", Journal of Polymer Science Part B: Polymer Physics, Vol. 43, No. 5, pp. 523-595, 2005

(14)A. Amash, and P. Zugenmaier : "Morphology and properties of isotropic and oriented samples of cellulose fibre-polypropylene composites", Polymer, Vol. 41, No. 4, pp. 1589-1596, 2000

(15) Min Kang Seo, and Soo Jin Park : "Electrical resistivity and rheological behaviors of carbon nanotubes-filled polypropylene composites", Chemical Physics Letters, Vol. 395, No. 1-3, pp. 44-48, 2004

(16) Dimitrios Bikiaris : "Microstructure and Properties of Polypropylene/Carbon Nanotube Nanocomposites", Materials, Vol. 3, No. 4, pp. 2884-2946, 2010

(17) S.C. Tjong, G.D. Liang, and S.P. Bao : "Electrical behavior of polypropylene/multiwalled carbon nanotube nanocomposites with low percolation threshold", Scripta Materialia, Vol. 57, No. 6, pp. 461-464, 2007

(18) K. Prashantha, J. Soulestin, M. F. Lacrampe, M. Claes, G. Dupin, and P. Krawczak : "Multi-walled carbon nanotube filled polypropylene nanocomposites based on masterbatch route: Improvement of dispersion and mechanical properties through PP-g-MA addition", Exress Polymer Letters, Vol, 2, No. 10, pp. 735-745, 2008

(19) Jooheon Kim, Hyungu Im, and M.H. Cho : "Tribological performance of fluorinated polyimide-based nanocomposite coatings reinforced with PMMA-grafted-MWCNT", Wear, Vol. 271, No. 7-8, 1029-1038, 2011

(20)Zhiqiang Chen, Xiujuan J. Dai, , Kevin Magniez, Peter R. Lamb, David Rubin de Celis Leal, Bronwyn L. Fox, and Xungai Wang : "Improving the mechanical 
properties of epoxy using multiwalled carbon nanotubes functionalized by a novel plasma treatment", Composites Part A: Applied Science and Manufacturing, Vol. 45, No. 2, pp. 145-152, 2013

(21) Suryasarathi Bose, Rupesh A. Khare, and Paula Moldenaers : "Assessing the strengths and weaknesses of various types of pre-treatments of carbon nanotubes on the properties of polymer/carbon nanotubes composites: A critical review", Polymer, Vol. 51, No. 5, pp. 975-993, 2010

(22)Blaž Likozar, and Zoltan Major : "Morphology, mechanical, cross-linking, thermal, and tribological properties of nitrile and hydrogenated nitrile rubber/multi-walled carbon nanotubes composites prepared by melt compounding: The effect of acrylonitrile content and hydrogenation", Applied Surface Science, Vol. 257, No. 2, pp. 565-573, 2010

(23) W. Leelapornpisit, Ton M. That, Perrin F Sarazin, , K.C Cole, J Denault, B Simard : "Effect of carbon nanotubes on the crystallization and properties of polypropylene", Journal of Polymer Science Part B: Polymer Physics, Vol. 43, No. 18, pp. 2445-2453, 2005

(24) Moncy V. Jose, Derrick Dean, James Tyner, Gary Price, and Elijah Nyairo : "Polypropylene/carbon nanotube nanocomposite fibers: Process-morphology- property relationships", Journal of Applied Polymer Science, Vol. 103, No. 6, pp. 3844-3850, 2007

(25) Amir Bahram Kaganj, Ali Morad Rashidi, Rouhollah Arasteh, and Sohrab Taghipoor : "Crystallisation behaviour and morphological characteristics of poly(propylene)/multi-walled carbon nanotube nanocomposites", Journal of Experimental Nanoscience, Vol. 4, No. 1, pp. 21-34, 2009 